\title{
Propranolol suppresses the proliferation and induces the apoptosis of liver cancer cells
}

\author{
FANG WANG ${ }^{1-5^{*}}$, HUI LIU ${ }^{3-5^{*}}$, FENGMEI WANG ${ }^{2-5}$, RUICHENG XU ${ }^{6,7}$, PENG WANG $^{3-5}$, \\ FEI TANG ${ }^{2-5}$, XU ZHANG ${ }^{2-5}$, ZHENGYAN ZHU ${ }^{3-5}, \mathrm{HONGMIN} \mathrm{LV}^{2-5}$ and TAO HAN ${ }^{2-5}$ \\ ${ }^{1}$ The Third Central Clinical College of Tianjin Medical University; ${ }^{2}$ Department of Gastroenterology and Hepatology of \\ Tianjin Third Central Hospital; ${ }^{3}$ Tianjin Institute of Hepatobiliary Disease; ${ }^{4}$ Tianjin Key Laboratory of Artificial Cell; \\ ${ }^{5}$ Artificial Cell Engineering Technology Research Center of Public Health Ministry; ${ }^{6}$ Tianjin Key Laboratory for \\ Biomarkers of Occupational and Environmental Hazard; ${ }^{7}$ Logistics University of \\ Chinese People's Armed Police Force, Tianjin 300170, P.R. China
}

Received August 11, 2017; Accepted December 13, 2017

DOI: $10.3892 / \mathrm{mmr} .2018 .8476$

\begin{abstract}
An increasing amount of evidence indicates that the inhibition of $\beta$ adrenergic signaling can result in the inhibition of tumor growth. However, the role of propranolol in liver cancer and the underlying mechanism remain to be elucidated. The present study aimed to investigate the role of propranolol in liver cancer cell lines and provide evidence for further clinical study. Propranolol was added at different concentrations to HepG2 and HepG2.2.15 liver cancer cells and HL-7702 normal human liver cells. The proliferation of the cell lines was monitored by live-cell imaging at a range of time intervals. Immunofluorescence using DAPI and Hoechst 33342/propidium iodide (PI) staining, Annexin V-FITC/PI double-staining flow cytometry, western blotting and reverse transcription-quantitative polymerase chain reaction were used to investigate the effect of propranolol on liver cancer cell apoptosis. The proliferation of HepG2 and HepG2.2.15 cells was inhibited by 40 and $80 \mu \mathrm{mol} / 1$ propranolol. However, the proliferation of HL-7702 cells was not affected by $<160 \mu \mathrm{mol} / 1$ propranolol. Propranolol treatment decreased the expression of adrenergic receptor $\beta-2$ to a greater extent than adrenergic receptor $\beta-1$, and induced apoptosis in the liver cancer cells. The apoptotic rates of HepG2 and HepG2.2.15 cells increased following treatment with
\end{abstract}

Correspondence to: Dr Tao Han, Department of Gastroenterology and Hepatology of Tianjin Third Central Hospital, 83 Jintang Road, Hedong, Tianjin 300170, P.R. China

E-mail: hantaomd@126.com

${ }^{*}$ Contributed equally

Abbreviations: HBV, hepatitis B virus; PFA, paraformaldehyde; PI, propidium iodide

Key words: apoptosis, cell cycle, cell proliferation, liver cancer, propranolol hydrochloride propranolol, while the apoptotic rate of HL-7702 cells was not affected. Propranolol promoted poly (ADP-ribose) polymerase cleavage and decreased the expression of full-length caspase-3 in liver cancer cell lines; it induced S-phase arrest in HepG2 and HepG2.2.15 cell lines, while HL-7702 cells were arrested at the $G_{0} / G_{1}$ phase of the cell cycle. Thus, it was demonstrated that propranolol inhibited proliferation, promoted apoptosis and induced S-phase arrest in HepG2 and HepG2.2.15 cells.

\section{Introduction}

The annual mortality rate of liver cancer ranks second among the malignant neoplasms worldwide in men. An estimated 782,500 new liver cancer cases and 745,500 mortalities occurred worldwide during 2012, with approximately half of all cases of liver cancer and mortality occurring in China (1). Liver cancer initially develops without symptoms, progresses rapidly, is associated with a poor prognosis and poses a serious threat to human health (2).

An increasing amount of evidence suggests that $\beta$ adrenergic signaling serves an essential role in progression of a variety of tumor types (3). Clinical epidemiological studies on the application of $\beta$ receptor blockers and the reduction of tumor metastasis demonstrated that $\beta$ receptor blockers decreased the development, metastasis, recurrence and tumor-associated mortality rate (4) of various types of solid tumor, including breast cancer $(5,6)$, thyroid cancer $(7)$, liver metastases (8) and pancreatic cancer (9). This suggests that $\beta$ receptor blockers may be suitable as a novel adjuvant therapy for tumors. However, another study observed that $\beta$ receptor blockers did not improve the survival rate of patients with breast cancer (10).

Among the aforementioned studies, the nonselective $\beta$ receptor blocker propranolol was the most frequently investigated. Propranolol demonstrates high safety and tolerance, has been used in clinical practice for $>40$ years and it is a recommended first-line oral medication for infantile hemangioma (11). Furthermore, propranolol has been clinically applied in patients with liver cirrhosis and liver cancer for a number of years, as a first-line prophylaxis for esophageal and 
gastric variceal bleeding (12). The present study aimed to determine whether propranolol, in addition to reducing the portal vein pressure in patients with liver cirrhosis, exhibits an anti-tumor effect in liver cancer.

In the present study, the effect of propranolol administered at different concentrations and time intervals on the proliferation of the human liver cancer cell lines HepG2, HepG2.2.15 and the normal human liver cell line HL-7702 was investigated. Experiments were also performed to determine the effect of propranolol on the rate of apoptosis and cell cycle distribution, detect the alterations in the expression of $\beta$ receptors on the cell membrane and determine the biological influences exerted on the three cell lines. The results of the present study demonstrated that propranolol inhibited liver cancer cell proliferation and induced apoptosis and S-phase arrest, thus exerting an anti-tumor effect on the liver cancer cells.

\section{Materials and methods}

Experimental materials and instruments. HepG2, HepG2.2.15 and HL-7702 cell lines were routinely maintained and subcultured in the laboratory. Propranolol hydrochloride was purchased from Sigma-Aldrich (Merck KGaA, Darmstadt, Germany). Monoclonal antibodies against adrenergic receptor $\beta$-1 (ADRB1; cat. no. 12271), $\beta$-2 (ADRB2; cat. no. 8513), caspase-3 (cat. no. 9665) and poly (ADP-ribose) polymerase (PARP; cat. no. 9532) were purchased from Cell Signaling Technology, Inc. (Danvers, MA, USA). $\beta$-actin rabbit polyclonal antibody (cat. no. E12-051) was purchased from EnoGene Biotech Co., Ltd. (Nanjing, China); Dulbecco's modified Eagle's medium (DMEM)/F12 culture medium and premium fetal bovine serum (FBS) were purchased from Biological Industries (Kibbutz Beit-Haemek, Israel). An Annexin V-fluorescein isothiocyanate (FITC)/propidium iodide (PI) Apoptosis Detection kit was purchased from EnoGene Biotech Co., Ltd. (Nanjing, China). RNase A was purchased from Takara Bio, Inc. (Otsu, Japan). PI dye, 4\% paraformaldehyde (PFA), Triton X-100 and DAPI dye were all purchased from Beijing Leagene Biotech Co., Ltd. (Beijing, China). Trypsin was purchased from Sangon Biotech Co., Ltd. (Shanghai, China) and Alexa Fluor 546-conjugated donkey anti-rabbit IgG secondary antibody (cat. no. A10040) was purchased from Thermo Fisher Scientific, Inc. (Waltham, MA, USA). The IncuCyte ZOOM second-generation live-cell imaging and analysis system was purchased from Essen Bioscience (Ann Arbor, MI, USA). A BD FACSCanto II flow cytometerwas purchased from BD Biosciences (Franklin Lakes, NJ, USA). The CSP-IIventilator was purchased from Beijing Chengwei Lab-Equipment Engineering Technology Co., Ltd. (Beijing, China) and the MCO-20AIC carbon dioxide incubator was purchased from SANYO Electric Co., Ltd. (Osaka, Japan). The ViiATM7thermocycler was purchased from Applied Biosystems (Thermo Fisher Scientific, Inc.).

Drug preparation. Propranolol hydrochloride (1.0 g) was dissolved in $20 \mathrm{ml}$ of distilled water to form a working solution with a concentration of $169 \mathrm{mmol} / \mathrm{l}$. Subsequently, $1 \mathrm{ml}$ of working solution was added to $9.6 \mathrm{ml}$ of distilled water to form a stock solution with a concentration of $16 \mathrm{mmol} / \mathrm{l}$. The stock solution was filtered through a $0.22-\mu \mathrm{m}$ microporous membrane and stored at $4{ }^{\circ} \mathrm{C}$ for future use. The stock solution was diluted to different concentrations $(2.5,5,10,20,40,80,160$ and $320 \mu \mathrm{mol} / \mathrm{l})$ to determine a suitable concentration for the treatment of liver cancer cells.

Cell culture. HepG2, HepG2.2.15 and HL-7702 cells were cultured in DMEM/F12 medium containing 6\% FBS with $100 \mathrm{U} / \mathrm{ml}$ penicillin and $100 \mu \mathrm{g} / \mathrm{ml}$ streptomycin. Cells were incubated at $37^{\circ} \mathrm{C}$ supplemented with $5 \% \mathrm{CO}_{2}$ in a humidified incubator. The culture medium was removed at cell subculture and the cells were washed twice with physiological saline. Trypsin was added and cells were incubated at $37^{\circ} \mathrm{C}$ for $3-5 \mathrm{~min}$. When the cells rounded up and separated from each other, the trypsin was removed and the cells were tapped off the wall of the flask prior to adding fresh medium and the cells were transferred into a centrifuge tube. The suspended cells were centrifuged at $92 \mathrm{x} \mathrm{g}$ at $25^{\circ} \mathrm{C}$ for $3 \mathrm{~min}$ and the supernatant was discarded. Fresh medium was added to resuspend the cells, and the solution was thoroughly mixed prior to placing in the aforementioned incubator. For cell freezing, $1 \mathrm{ml}$ cell cryopreservation solution (culture medium 9:1 DMSO) was added to the cell pellet and mixed thoroughly prior to being transferred into a cryotube for long-term storage in liquid nitrogen.

Observation of cell proliferation using a live-cell imaging and analysis system. Cells in the logarithmic growth phase were obtained and the culture medium was removed, prior to washing twice with physiological saline. Subsequently, $0.2 \mathrm{ml}$ $0.25 \%$ trypsin was added to the washed cells and incubated at $37^{\circ} \mathrm{C}$ for $2-5 \mathrm{~min}$, prior to adding $2 \mathrm{ml} \mathrm{DMEM} / \mathrm{F} 12$ medium to terminate the trypsinization. The trypsinized cells were collected, counted, and seeded in a 96-well plate at a density of $1 \times 10^{4} / \mathrm{ml}$. The 96 -well plate was incubated at $37^{\circ} \mathrm{C}$ supplemented with $5 \% \mathrm{CO}_{2}$ overnight. The following day, the cells were observed to confirm their health, and culture medium was removed, prior to washing twice with physiological saline. Subsequently, culture medium containing propranolol at a range of concentrations $(0,2.5,5,10,20,40,80,160$ and $320 \mu \mathrm{mol} / \mathrm{l}$ ) was added to the cells, which were then transferred to the IncuCyte ZOOM incubator.

Two images of each well were captured every $6 \mathrm{~h}$, with a total observation period of $48 \mathrm{~h}$; the 96-well plate was not moved during this time. IncuCyte 2104A software (Essen Bioscience) was used for the analysis of cell confluence and cell count in each image, and growth curves were generated. The cell proliferation ratio was calculated as the ratio between the cell confluence (\%) of cells treated with propranolol a teach concentration and cells treated with $0 \mu \mathrm{mol} / 1$ propranolol at the same time point. The cell proliferation ratio at $6,12,18,24,30,36,42$ and $48 \mathrm{~h}$ was calculated as the ratio between cell confluence (\%) at each time point and the time when the drug was added $(0 \mathrm{~h})$. Each condition was performed in triplicate. The whole experiment was repeated three times.

Immunofluorescence detection of $A D R B 1$ and $A D R B 2$ and their alterations. Cells in the logarithmic growth phase were seeded in a 48 -well plate and incubated at $37^{\circ} \mathrm{C}$ in $5 \% \mathrm{CO}_{2}$ overnight. The cells were observed, to confirm their health, prior to removing the culture medium and washing twice with physiological saline. Culture medium containing 0 or 
$40 \mu \mathrm{mol} / 1$ propranolol was added to the cells, which were incubated at $37^{\circ} \mathrm{C}$ in $5 \% \mathrm{CO}_{2}$ for $48 \mathrm{~h}$. Subsequently, the culture medium was removed and cells were washed three times with 1X PBS, for 3 min each time.

A total of $100 \mu 14 \%$ PFA was added to each well and incubated at room temperature for 15-30 min. Subsequently, the PFA was discarded and the cells were washed three times with 1X PBS for 3 min each time. This was followed by the addition of $100 \mu 10.1 \%$ Triton X-100 into each well and incubation at room temperature for $30 \mathrm{~min}$. Following the permeabilization with Triton X-100, cells were washed three times with $1 \mathrm{X}$ PBS for $3 \mathrm{~min}$ each time.

A total of $100 \mu 11 \%$ bovine serum albumin (Sigma-Aldrich; Merck KGaA, Darmstadt, Germany) was added to each well and incubated at room temperature for $30 \mathrm{~min}$. Antibodies against ADRB1 and 2 were diluted to 1:100 in 1X PBS. A total of $100 \mu \mathrm{l}$ ADRB1 or 2 antibody solution was added to each well and incubated at $4^{\circ} \mathrm{C}$ overnight. The following day, cells were washed three times with $1 \mathrm{X}$ PBS, 3 min each time. Fluorescent secondary antibodies were diluted 1:200 in 1X PBS. Diluted secondary antibodies $(100 \mu \mathrm{l})$ were added to each well and incubated in the dark at room temperature for $1 \mathrm{~h}$.

DAPI (100 $\mu \mathrm{l}$; dilution, 1:1,000) or Hoechst 33342/PI was added to the wells and incubated in the dark at room temperature for 2-3 min. Subsequently, DAPI was removed from the cells and they were washed with PBS, followed by immediate imaging using an inverted fluorescence microscope. Captured images were analyzed using Image-Pro Plus5.0 image analysis software (Media Cybernetics, Inc., Rockville, MD, USA). Each condition was performed in triplicate. The whole experiment was repeated three times.

Western blotting. Following the treatment of the three cell lines with 0,40 or $80 \mu \mathrm{mol} / 1$ propranolol for $48 \mathrm{~h}$, cells were lysed with radioimmunoprecipitation assay lysis buffer (CW2333S; Cowin Biotech Co., Ltd, Beijing, China), proteinase/phosphatase inhibitor cocktail (cat. no. PP1301; Aidlab Biotechnologies Co., Ltd., Beijing, China) and phenylmethanesulfonyl fluoride (EnoGene, Nanjing, China) at a 100:1:1 ratio. A bicinchoninic protein assay kit (CW0014S; Cowin Biotech Co., Ltd., Beijing, China) was subsequently used to determine protein concentration. A total of $20 \mu \mathrm{g}$ protein per lane was separated by $10-12 \%$ SDS-PAGE and electrotransferred onto polyvinylidene fluoride membranes. Subsequently, the transferred membranes were blocked with 5\% skimmed milk for $2 \mathrm{~h}$ at $25^{\circ} \mathrm{C}$ and incubated with primary monoclonal antibodies, including ADRB1, ADRB2, caspase-3, PARP and $\beta$-actin (all dilutions, $1: 1,000)$ at $4^{\circ} \mathrm{C}$ overnight. The membranes were then washed with Tris- $\mathrm{HCl}$ and incubated with a goat anti-rabbit IgG-horseradish peroxidase conjugated secondary antibody (dilution, 1:4,000; Abmart, Inc., Shanghai, China) at $37^{\circ} \mathrm{C}$ for $1.5 \mathrm{~h}$. Following incubation with an enhanced chemiluminescence reagent (BeyoECL Star; Beyotime Institute of Biotechnology, Shanghai, China) for $10 \mathrm{~min}$ at $25^{\circ} \mathrm{C}$, a dark chamber was used to develop images. The protein bands were quantified using Image J software (version 1.46r; National Institutes of Health, Bethesda, MD, USA).

Reverse transcription-quantitative polymerase chain reaction $(R T-q P C R)$. RT-qPCR was used to detect the expression of ADRB2 mRNA in the three cell lines. Total RNA was extracted from the cells using TRIzol ${ }^{\circledR}$ reagent (Thermo Fisher Scientific, Inc.) according to the manufacturer's instructions. Total RNA ( $3 \mu \mathrm{g})$ was reverse transcribed to cDNA using a RevertAid First Strand cDNA Synthesis kit (Thermo Fisher Scientific, Inc.), with $1 \mu$ l Oligo(dT)18, 5X Reaction Buffer (4 $\mu \mathrm{l}$ ), RiboLock RNase Inhibitor $(1 \mu \mathrm{l})$, dNTP Mix $2 \mu \mathrm{l}$, RevertAid Reverse Transcriptase $1 \mu \mathrm{l}$ and $\mathrm{ddH}_{2} \mathrm{O}$ to supplement to a total volume of $20 \mu \mathrm{l}$. The synthesis conditions for cDNA were $5 \mathrm{~min}$ at $25^{\circ} \mathrm{C}, 60 \mathrm{~min}$ at $42^{\circ} \mathrm{C}$ and $15 \mathrm{~min}$ at $70^{\circ} \mathrm{C}$.

SYBR Premix Ex Taq $^{\mathrm{TM}}$ II (Tli RNaseH Plus; cat. no. RR820A; Takara Bio, Inc.) was used for the PCR reaction, including $10 \mu \mathrm{l}$ SYBR Premix Ex Taq II (Tli RNaseH Plus), $0.4 \mu$ l ROX Reference Dye II, $0.8 \mu 1$ ADRB2 forward primer (5'-GCCTGTGCTGATCTGGTCAT-3'), $0.8 \mu 1$ ADRB2 reverse primer (5'-AATGGAAGTCCAAAACTC GCA-3'; primers synthesized by Invitrogen; Thermo Fisher Scientific, Inc.), $2.0 \mu \mathrm{l}$ cDNA template and $6.0 \mu \mathrm{lddH} 2 \mathrm{O}$, in a $20 \mu \mathrm{l}$ reaction system. The following conditions were used for PCR: $10 \mathrm{~min}$ at $95^{\circ} \mathrm{C}, 40$ cycles of $15 \mathrm{sec}$ at $95^{\circ} \mathrm{C}$ and $60 \mathrm{sec}$ at $60^{\circ} \mathrm{C}$. GAPDH was used as a reference gene (forward, 5'-GACCCCTTCATTGACCTCAAC-3' and reverse, 5'-CGC TCCTGGAAGATGGTGAT-3'; Invitrogen; Thermo Fisher Scientific, Inc.). According to the analysis of the amplification and melting curves, the relative expression of the ADRB2 gene was calculated using the $2^{-\Delta \Delta \mathrm{Cq}}$ method (13).

Detection of apoptosis using flow cytometry. Following incubation with 0,40 or $80 \mu \mathrm{mol} / 1$ propranolol for $48 \mathrm{~h}$, culture medium was removed from the cells and transferred into a centrifuge tube. Adherent cells were washed with PBS once prior to trypsinization with trypsin (with $0.25 \%$ EDTA). The trypsinized cells were added to back into the culture medium and mixed well prior to centrifugation $92 \mathrm{x} \mathrm{g}$ for $5 \mathrm{~min}$ at $25^{\circ} \mathrm{C}$. The supernatant was discarded and the cell pellet was gently resuspended in PBS and counted. A total of $4 \times 10^{5}$ cells were then centrifuged at $92 \mathrm{x}$ g for $5 \min 25^{\circ} \mathrm{C}$. The supernatant was discarded and $500 \mu \mathrm{l}$ binding buffer (apoptosis detection kit; EnoGene Biotech Co., Ltd.) was added to gently resuspend the cells. Subsequently, cells were filtered through a 400-mesh filter to form a single-cell suspension, followed by the addition of $5 \mu \mathrm{l}$ Annexin V-FITC and $5 \mu \mathrm{l}$ PI, with gentle mixing. The cells were incubated in the dark at room temperature for $10 \mathrm{~min}$ and immediately subjected to flow cytometry detection. The results were analyzed using FlowJo software (version 7.6.1; Tree Star, Inc., Ashland, OR, USA). Each condition was performed in triplicate. The whole experiment was repeated three times.

Detection of cell cycle distribution using flow cytometry. Following incubation with 0,40 or $80 \mu \mathrm{mol} / 1$ propranolol for $48 \mathrm{~h}$, the cell culture medium was removed from the cells and transferred to a centrifuge tube. Adherent cells were washed with PBS twice, trypsinized and resuspended. The cell suspension was centrifuged at $138 \mathrm{x}$ g at $4^{\circ} \mathrm{C}$ for $5 \mathrm{~min}$. The supernatant was discarded and the cells were washed with precooled $1 \mathrm{X}$ PBS once and centrifuged at 1,000 x g at $4^{\circ} \mathrm{C}$ for $5 \mathrm{~min}$. The supernatant was discarded, and the cell pellet was added to $5 \mathrm{ml}$ of $70 \%$ ethanol, gently mixed and incubated at $4^{\circ} \mathrm{C}$ overnight. The following day, the cells were 

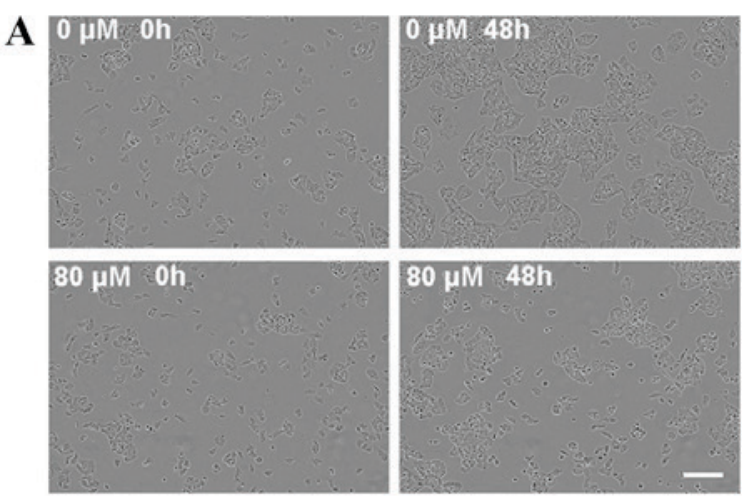

B

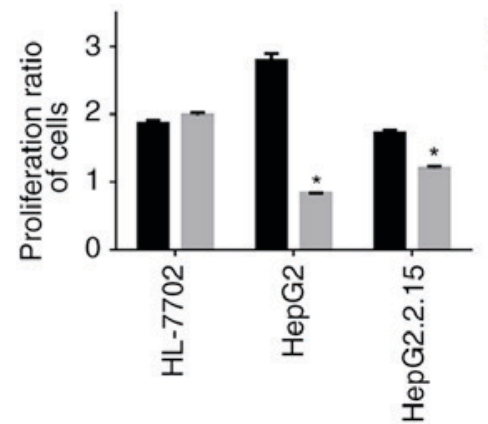

$0 \mu \mathrm{mol} / \mathrm{l}$
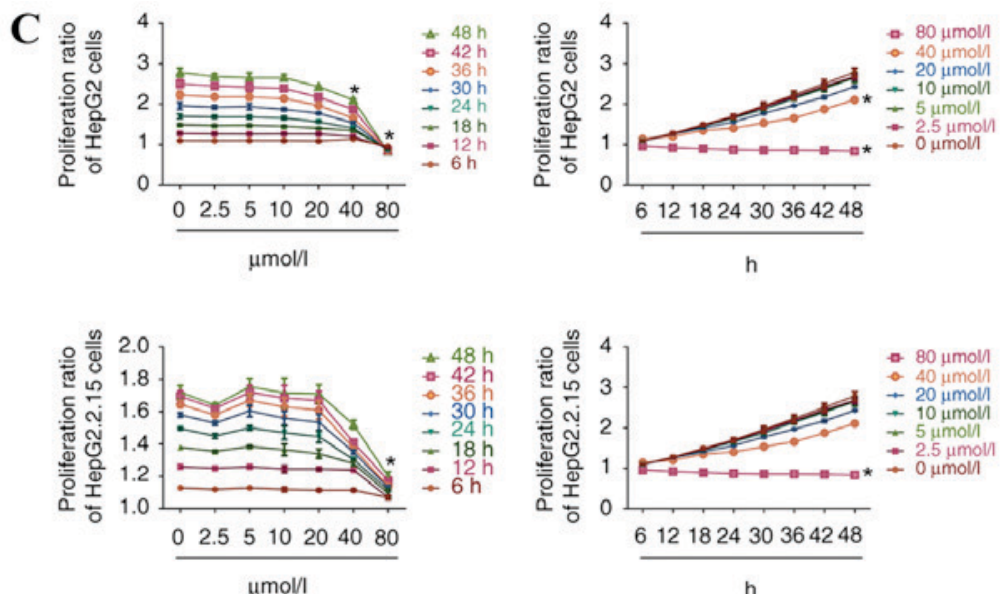

$\mu \mathrm{mol} / \mathrm{l}$

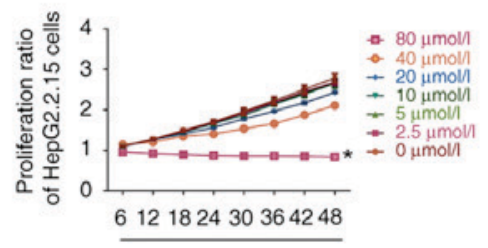

h
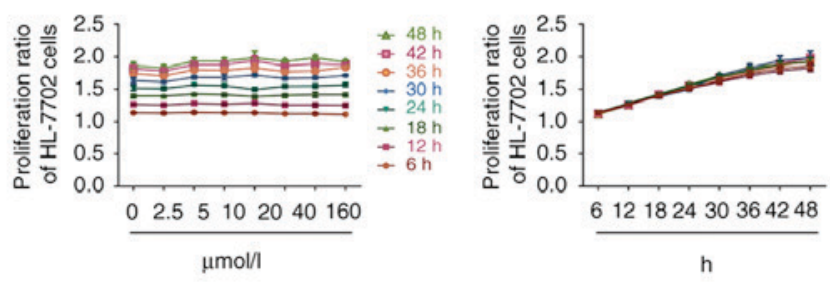

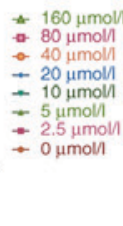

Figure 1. Propranolol hydrochloride treatment inhibits the proliferation of HepG2 and HepG2.2.15 cells. (A) Following $48 \mathrm{~h}$ of incubation with $80 \mu$ mol/1 propranolol hydrochloride, the confluence of HepG2 cells was decreased, based on the analysis performed using the IncuCyte ZOOM live-cell imaging and analysis system. Scale bar, $200 \mu \mathrm{m}$. (B) In HepG2 and HepG2.2.15 cells, the cell proliferation ratio was decreased at $48 \mathrm{~h}$ of incubation with $80 \mu \mathrm{mol} / 1$ propranolol. However, propranolol exhibited no effect on the proliferation ratio of HL-7702 cells. (C) Propranolol hydrochloride suppressed the proliferation of HepG2 and HepG2.2.15 cells in a time- and concentration-dependent manner, while the proliferation of HL-7702 cells remained unaltered. "P<0.05 vs. $0 \mu$ mol/1.

centrifuged at $138 \mathrm{x}$ g for $5 \mathrm{~min}$ at $25^{\circ} \mathrm{C}$ and the supernatant was discarded. The pellet was washed three times with precooled $1 \mathrm{X}$ PBS, for $3 \mathrm{~min}$ each time. The cell suspension was centrifuged at $138 \mathrm{x} \mathrm{g}$ for $5 \mathrm{~min}$ at $25^{\circ} \mathrm{C}$ and the supernatant was discarded. The pellet was added to a $0.4-\mathrm{ml}$ PI mixture (with $4 \mu \mathrm{l}$ RNase) in the dark and stained for $30 \mathrm{~min}$ at $25^{\circ} \mathrm{C}$ prior to immediate detection using a flow cytometer. The results were analyzed using FlowJo 7.6.1 software (Tree Star, Inc.).

Statistical analysis. Data were statistically analyzed using SPSS 17.0 software (SPSS, Inc., Chicago, IL, USA). Quantitative results were expressed as the mean \pm standard deviation. A t-test was used to compare differences between two groups, and a one-way analysis of variance followed by the Least-significant difference post hoc test was used to compare differences among multiple groups. $\mathrm{P}<0.05$ was considered to indicate a statistically significant difference.

\section{Results}

Propranolol inhibits the proliferation of liver cancer cells. IncuCyte ZOOM phase-contrast imaging revealed the growth rates as indicated by the cell confluence (\%) of the three investigated cell lines.

When HepG2 cells were incubated with $80 \mu \mathrm{mol} / 1$ propranolol for $48 \mathrm{~h}$, cell confluence was reduced and a small number of cells became detached from the surrounding cells and suspended, suggesting the inhibition of cell proliferation (Fig. 1A). The proliferation ratio of HepG2 and HepG2.2.15 cells was significantly decreased at $48 \mathrm{~h}$ of treatment with $80 \mu \mathrm{mol} / \mathrm{l}$ propranolol $(\mathrm{P}<0.05)$, whereas the proliferation of HL-7702 cells was unaltered (Fig. 1B). The results demonstrated that at the same concentration, the inhibitory effect of propranolol on the proliferation ratio of HepG2 and HepG2.2.15 cells increased with the increase in duration of the treatment. At the same treatment time point, the inhibitory effect was enhanced with the increase in propranolol concentration. Therefore, propranolol hydrochloride suppressed liver cancer cell proliferation in a time and concentration dependent manner (Fig. 1C).

The proliferation ratio of HepG2 cells decreased after $18 \mathrm{~h}$ of treatment with $20 \mu \mathrm{mol} / 1$ propranolol $(\mathrm{P}<0.05)$ and after $48 \mathrm{~h}$ of treatment with 40 or $80 \mu \mathrm{mol} / 1$ of propranolol (both $\mathrm{P}<0.05)$. The proliferation ratio of HepG2.2.15 cells decreased when the cells were treated with $40 \mu \mathrm{mol} / 1$ propranolol for $18 \mathrm{~h}$ $(\mathrm{P}<0.05)$, and when treated with 40 or $80 \mu \mathrm{mol} / 1$ of propranolol for $48 \mathrm{~h}(\mathrm{P}<0.05)$. No inhibitory effect was observed following treatment with different propranolol concentrations for $48 \mathrm{~h}$ in HL-7702 cells.

Following the incubation of HepG2 and HepG2.2.15 cells with $160 \mu \mathrm{mol} / 1$ propranolol, and all three cell lines with $320 \mu \mathrm{mol} / 1$ propranolol, the adherent cells visibly shrank and the microscopic observation revealed a large number of floating cells (data not shown); therefore, statistical analysis of the cell proliferation ratio was not performed in the present study at these doses of treatment.

Propranolol decreases the expression of $\beta$ receptors for the three cell lines. The spatial distribution of ADRB1 and ADRB2 on HepG2, HepG2.2.15 and HL-7702 cells was measured by immunofluorescence. It was demonstrated that 

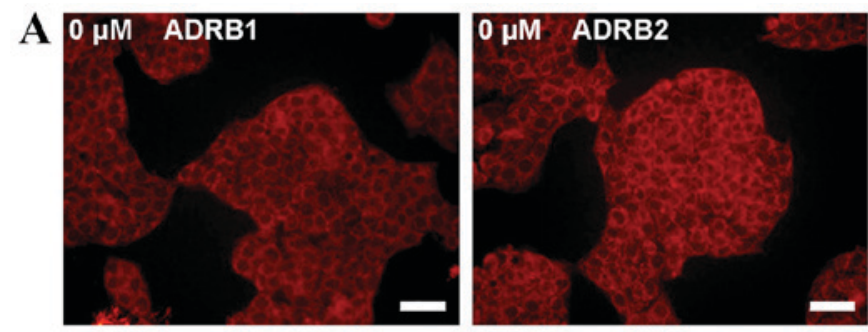

B
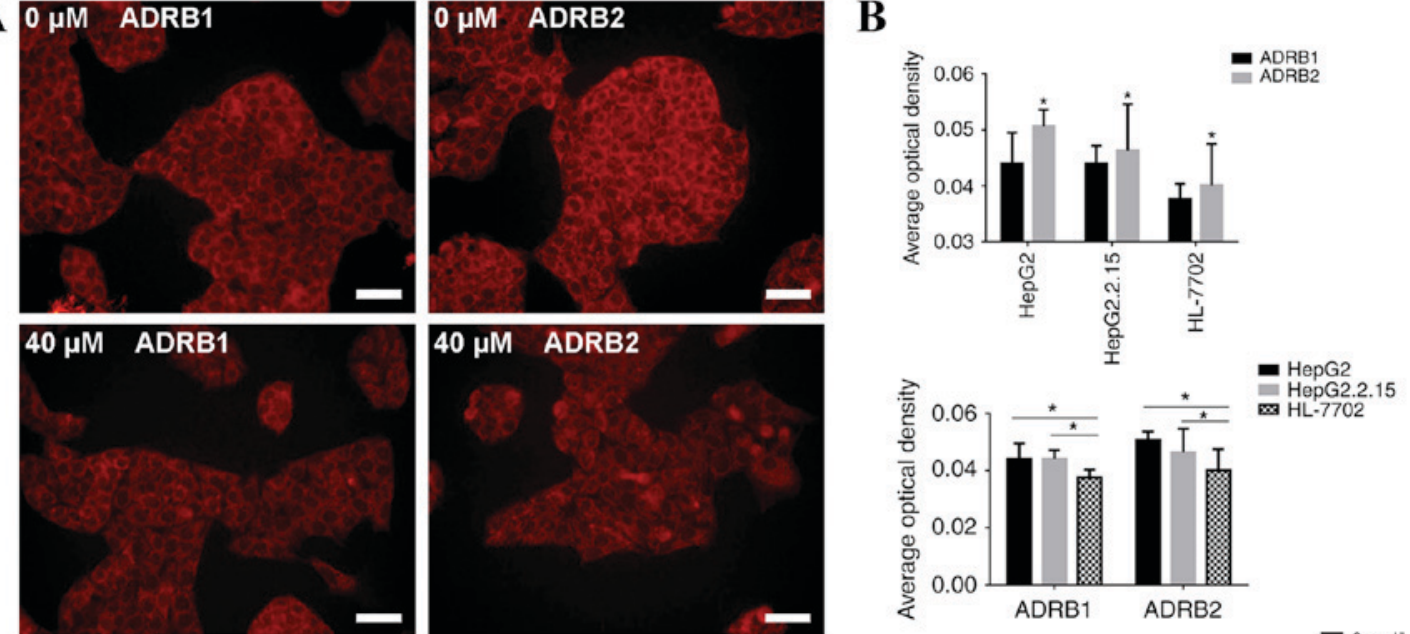

C
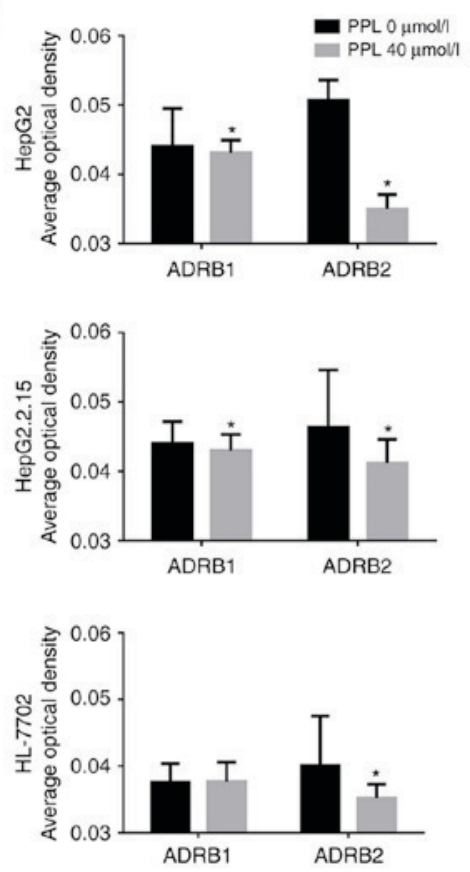

D
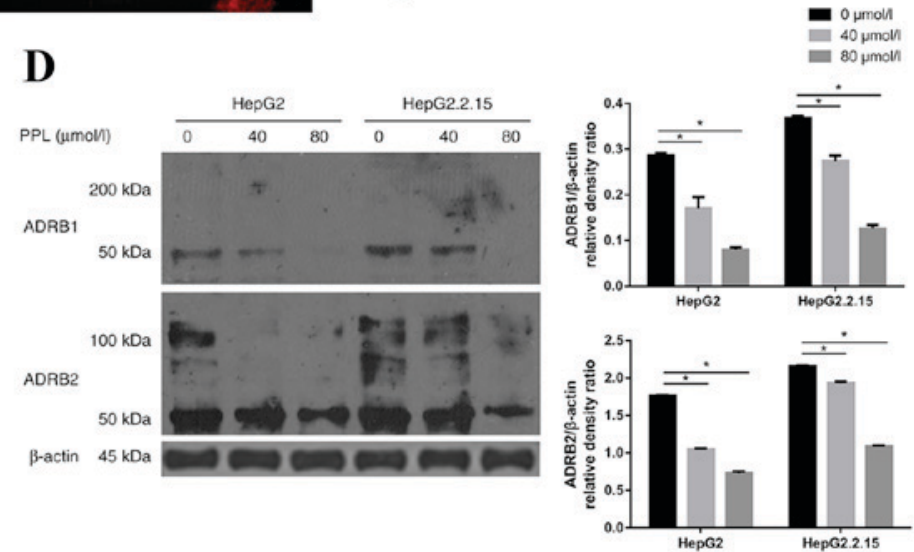

$\mathbf{E}$

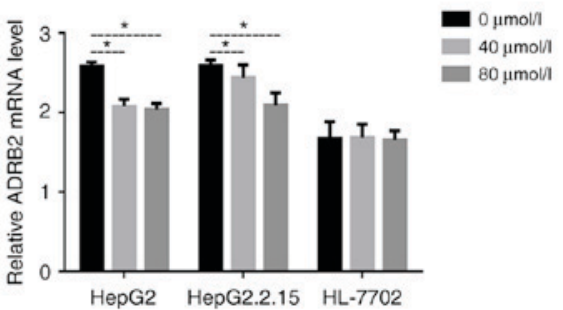

Figure 2. Inhibitory effect of PPL on the proliferation of liver cancer cells by the inhibition of ADRB2. (A) ADRB1 and ADRB2 were localized on the cell membrane of the three cell lines, as demonstrated by immunofluorescence. Scale bar, $50 \mu$ m. (B) The expression of ADRB1and ADRB2 on HepG2 and HepG2.2.15 cells was higher than HL-7702 cells. The expression of ADRB2 was higher than ADRB1 on all three cell lines. (C) PPL decreased the expression of ADRB1 and ADRB2, particularly ADRB2, on liver cancer cells, as demonstrated by immunofluorescence. (D) PPL treatment decreased the expression of ADRB1 and 2 in liver cancer cells, as demonstrated by western blotting. (E) ADRB2 mRNA expression was determined with reverse transcription-quantitative polymerase chain reaction. PPL decreased ADRB2 expression in a concentration-dependent manner in the HepG2 and HepG2.2.15 cells. * $<<0.05$. PPL, propranolol hydrochloride; ADRB1, adrenergic receptor $\beta-1$; ADRB2, adrenergic receptor $\beta-2$.

ADRB1 and ADRB2 were expressed on the membrane of the three cell lines, and were more highly expressed on HepG2 and HepG2.2.15 cells compared with HL-7702 cells $(\mathrm{P}<0.05)$. The expression of ADRB2 was higher than the expression of ADRB1 on all cell lines (all $\mathrm{P}<0.05$; Fig. $2 \mathrm{~A}$ and $\mathrm{B}$ ).

Propranolol $(40 \mu \mathrm{mol} / \mathrm{l}$; the lowest that inhibited the proliferation of HepG2 and HepG2.2.15 cells) was added to HepG2, HepG2.2.15 and HL-7702 cells, and the alterations in the expression of $\beta$ receptors on the membranes of the three cell lines were observed. The results demonstrated that treatment with propranolol decreased the expression of ADRB1 and ADRB2 on HepG2 and HepG2.2.15 cells (all $\mathrm{P}<0.05$ ), while only the expression of ADRB2 was decreased on HL-7702 cells $(\mathrm{P}<0.05)$. The decrease in the expression of
ADRB2 on the three cell lines was more pronounced than the expression of ADRB1 (Fig. 2C).

The protein expression of ADRB1 and ADRB2 in HepG2 and HepG2.2.15 cells decreased following treatment with 40 and $80 \mu \mathrm{mol} / 1$ propranolol for $48 \mathrm{~h}$, as demonstrated using western blotting (Fig. 2D). As propranolol treatment most markedly decreased the level of ADRB2 protein, the ADBR2 mRNA expression level was determined by RT-qPCR. Following incubation with propranolol for $48 \mathrm{~h}$, the relative ADRB2 mRNA level decreased in the liver cancer cells, but not in HL-7702 cells (Fig. 2E).

Propranolol affects the rate of apoptosis in liver cancer cell lines. The effect of propranolol on the apoptotic morphology 
A
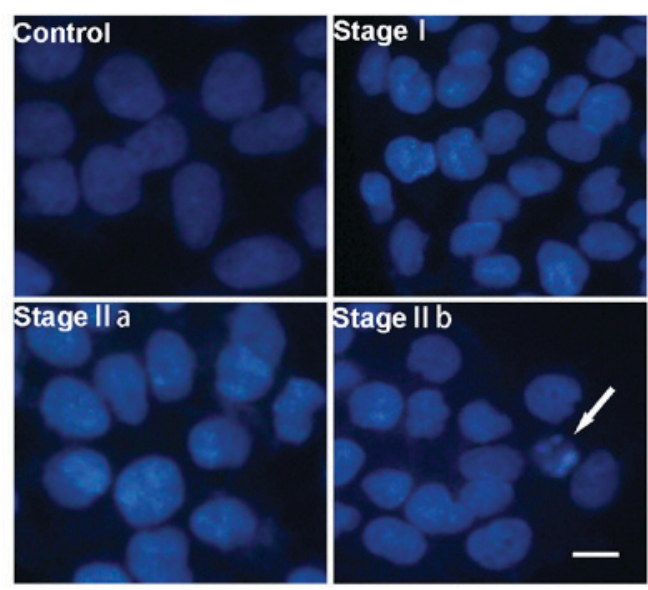

C
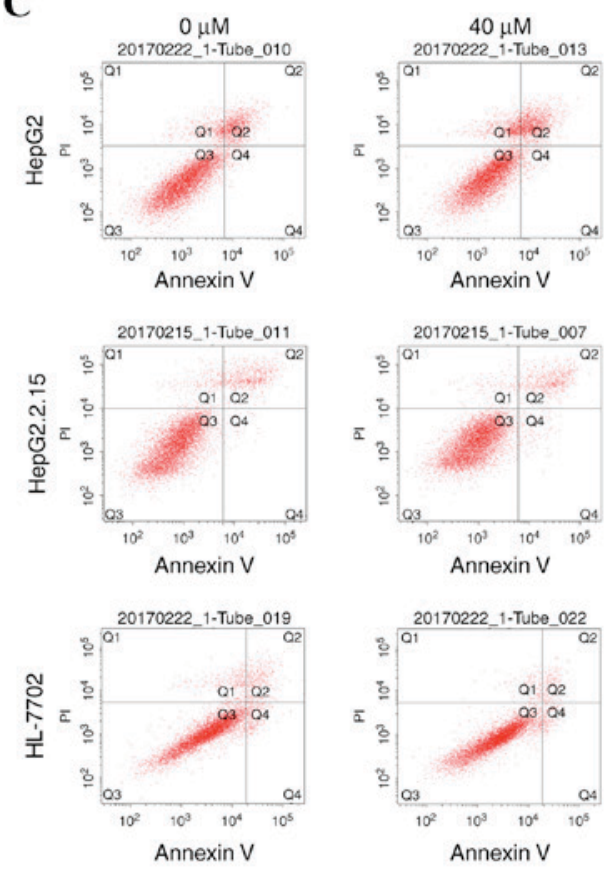

B

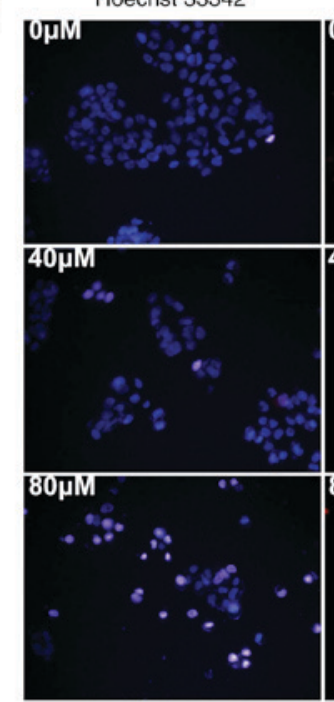

$\mathrm{Pl}$
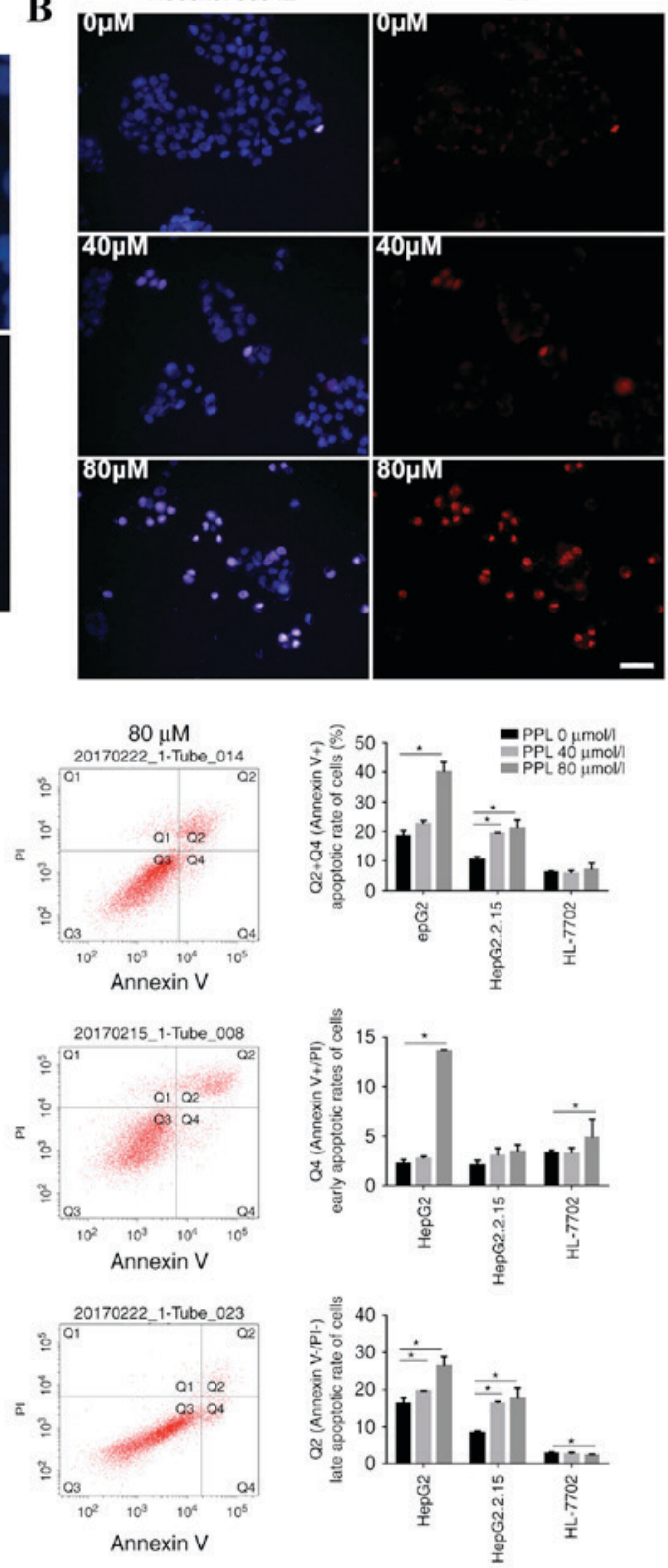

D

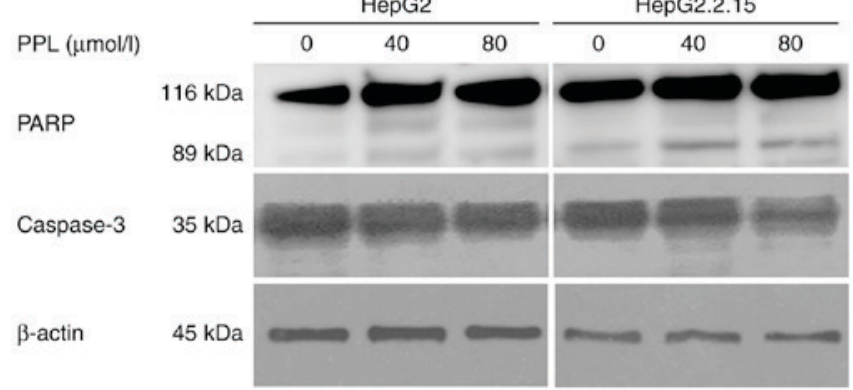

Figure 3. PPL treatment induced the apoptosis of HepG2 and HepG2.2.15 cells. (A) Representative DAPI staining images of HepG2 cells cultured with or without PPL for $48 \mathrm{~h}$. The nuclei of HepG2 without PPL treatment (the control) were homogeneously stained and regularly shaped. Following treatment with PPL, the HepG2 cells demonstrated the characteristics of stage I apoptosis; the nuclei of HepG2 cells were corrugated and chromatin condensation was visible. In stage IIa, the nuclei displayed chromatin condensation and marginalization. In stage IIb, the nuclei of HepG2 cells were cleaved and apoptotic bodies were formed. The white arrow indicates an apoptotic body. Scale bar, $25 \mu \mathrm{m}$. (B) Representative images of the Hoechst 33342/PI double staining of HepG2 cells cultured with different concentrations of PPL for $48 \mathrm{~h}$. Incubation with $80 \mu \mathrm{mol} / 1$ PPL induced the Hoechst 33342 (blue) and PI (red) staining of HepG2 cells, which was visibly increased compared with $0 \mu \mathrm{mol} / 1$ PPL. Scale bar, $50 \mu \mathrm{m}$. (C) PPL increased the rate of apoptosis for HepG2 and HepG2.2.15 cells, while it exhibited no significant effect on the apoptosis of HL-7702 cells, as demonstrated by flow cytometry. Q1, Annexin V-FITC-/PI ${ }^{+}$, necrotic cells; Q2, Annexin V-FITC $/ \mathrm{PI}^{+}$, late apoptotic cells; Q3, Annexin V-FITC-PI', viable cells; Q4, Annexin V-FITC +/PI', early apoptotic cells. The apoptotic rate was calculated based on the sum of quadrants 2 and 4, which included all Annexin V-FITC ${ }^{+}$cells. "P<0.05. (D) In HepG2 and HepG2.2.15 cells treated with different concentrations of PPL for $48 \mathrm{~h}$, the expression of full-length caspase 3 decreased, and expression of the PARP fragment (89 kDa) increased, as demonstrated by western blotting. PPL, propranolol hydrochloride; PI, propidium iodide; PARP, poly (ADP-ribose) polymerase. ${ }^{*}<0.05$. 

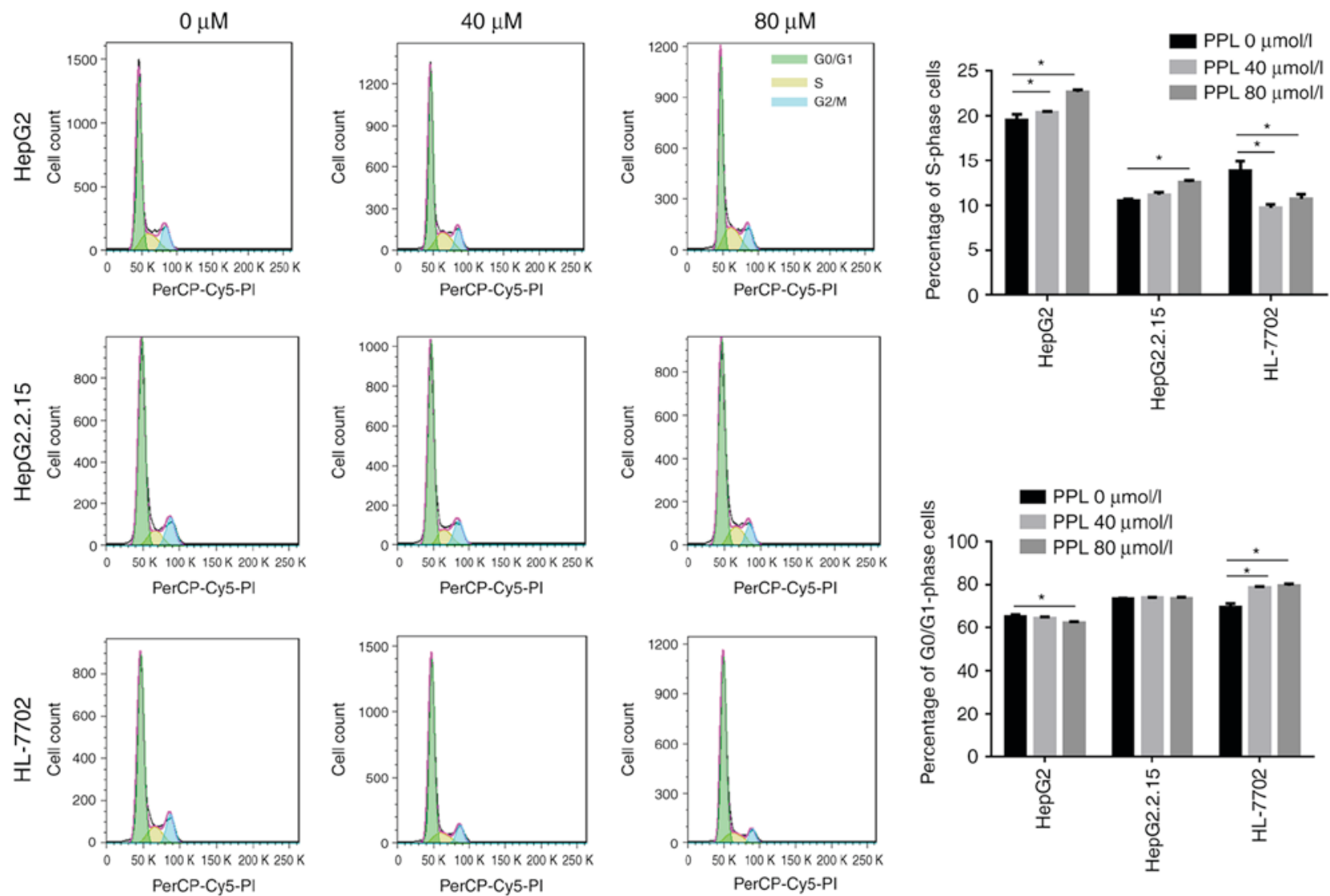

Figure 4. PPL treatment induced S phase arrest in liver cancer cells. The treatment of HepG2 and HepG2.2.15 cells with PPL induced a gradual increase in the proportion of cells in S-phase, indicating that the cell cycle was arrested in the S phase. However, the culture of HL-7702 cells with PPL resulted in a gradual increase in the percentage of $\mathrm{G}_{0} / \mathrm{G}_{1}$ phase cells, indicating that the cell cycle was arrested in the $\mathrm{G}_{0} / \mathrm{G}_{1}$ phase. PPL, propranolol hydrochloride; PI, propidium iodide. "P<0.05.

of liver cancer cells was observed under a microscopeby staining the nuclei with DAPI and Hoechst 33342/PI. The HepG2 cells treated with propranolol for $48 \mathrm{~h}$ demonstrated alterations in their nuclear chromatin that represented each stage of apoptosis, including stages I, IIa and IIb, and the formation of apoptotic bodies, suggesting that treatment with propranolol could induce apoptosis in liver cancer cells (Fig. 3A). Following Hoechst 33342/PI double staining, the number of apoptotic cells (strong blue staining) increased with the increase in propranolol concentration, indicating that the apoptosis of HepG2 cells occurred following the incubation with propranolol for $48 \mathrm{~h}$ (Fig. 3B).

Furthermore, Annexin V-FITC/PI double staining was used to quantitatively measure the rate of apoptosis. Cells incubated with 0,40 and $80 \mu \mathrm{mol} / 1$ propranolol for $48 \mathrm{~h}$ were subjected to flow cytometry detection. It was demonstrated that $80 \mu \mathrm{mol} / 1$ propranolol increased the rate of apoptosis of the HepG2 and HepG2.2.15 cell lines (both $\mathrm{P}<0.05$ ), while it exerted no influence on the apoptotic rate of HL-7702 cells (Fig. 3C). The same gate could not be used for all flow cytometry apoptosis assays due to alterations in the size and morphology of cells following the incubation with propranolol, particularly $160 \mu \mathrm{mol} / 1$ propranolol. Instead, a positive control was used in each sample to adjust the position of the gate. The location on the $\mathrm{X}$-axis and $\mathrm{Y}$-axis were then adjusted on the basis of the positive control data.

Following incubation with 40 and $80 \mu \mathrm{mol} / \mathrm{l}$ propranolol for $48 \mathrm{~h}$, the extent of PARP cleavage increased, whereas the expression of full-length caspase 3 ( $35 \mathrm{kDa}$ ) decreased in HepG2 and HepG2.2.15 cells (Fig. 3D). These results indicated that propranolol may have induced the apoptosis of liver cancer cells by promoting caspase-associated signaling.

Effect of treatment with propranolol on the cell cycle distribution of the three cell lines. Propranolol was demonstrated in the present study to promote the apoptosis of liver cancer cells. Subsequently, flow cytometry and PI staining were used to investigate whether cell cycle arrest occurred during propranolol-induced liver cancer cell apoptosis. It was demonstrated that the treatment of HepG2 and HepG2.2.15 cells with 40 or $80 \mu \mathrm{mol} / 1$ propranololincreased the proportion of cells in $\mathrm{S}$-phase (all $\mathrm{P}<0.05$ ), suggesting an $S$-phase arrest during the cell cycle. However, the incubation of HL-7702 cells with propranolol led to an increase in the number of $G_{0} / G_{1}$ phase cells (both $P<0.05$ ), suggesting that cells were arrested at the $G_{0} / G_{1}$ phase of the cell cycle (Fig. 4).

\section{Discussion}

Recent studies have indicated that propranolol hydrochloride treatment may reduce the progression, metastasis and recurrence of various tumors, and therefore reduce the tumor-associated mortality rate, through the inhibition of $\beta$ receptors (14-16), which may be suitable as a novel clinical adjuvant therapy against tumors (17). However, there is limited data regarding the anti-tumor effect of propranolol in liver 
cancer cells. The present study demonstrated that propranolol inhibited liver cancer cell proliferation by inhibiting the expression of ADRB2 and inducing apoptosis by activating caspase-associated signaling.

A previous meta-analysis reported that $\beta$ receptor blockers reduced the mortality rate of patients with liver cirrhosis. One potential explanation for this effect is the reduction in gastrointestinal bleeding by $\beta$ receptor blockers; another possible explanation is a reduction in the incidence of liver cancer (18). It was also demonstrated that propranolol reduced the 10-year cumulative incidence of liver cancer in patients with hepatitis C-associated cirrhosis (19). Liver cancer in patients in China primarily develops from hepatitis B virus (HBV)-associated liver cirrhosis and is frequently accompanied by an increase in $\alpha$-fetoprotein levels (20-22). The HepG2 cell line, the parental cell line of HepG2.2.15, has been reported to be misidentified; it was originally identified as a hepatocellular carcinoma cell line, but was later revealed to be derived from a hepatoblastoma (23). Hepatoblastoma is a tumor that originates from cells in the liver. At present, HepG2 is widely used to study liver cancer in vitro. Therefore, the present study was performed with HepG2 (which secretes $\alpha$-fetoprotein) and HepG2.2.15 (which expresses HBV antigen and secretes complete HBV particles) cells, as well as the human normal liver cell line HL-7702, to investigate the anti-tumor effect of propranolol.

It was initially demonstrated in the present study that $\beta$ receptors were localized on the cell membrane of the liver cancer cell lines and were more highly expressed in liver cancer cells compared with normal liver cells, and the expression was reduced by treatment with propranolol. Previous studies have reported that the expression of $\beta$ receptors in liver cancer patients was elevated, particularly ADRB2 (24,25). The results of the present study are therefore consistent with the results of previous in vitro and in vivo studies. Propranolol, as a nonselective receptor blocker, primarily affects ADRB2, with a lesser effect on ADRB1 (26), suggesting an anti-tumor effect of propranolol. The results of the present study demonstrated that propranolol reduced the expression of the ADRB2 receptor on the liver cancer cell membranes to a greater extent than the expression ofADRB1, suggesting that ADRB2 may serve a more important role in liver cancer. Previous studies indicated that the ADRB2 receptor may be a prognostic indicator for liver cancer (27), and that the ADRB2 receptor signaling pathway is associated with liver cancer cell proliferation and autophagy (28), while the underlying mechanisms remain to be elucidated.

Furthermore, the present study confirmed that propranolol inhibited the proliferation of HepG2 and HepG2.2.15 cells. The inhibitory effect of propranolol on liver cancer cells was enhanced with a prolonged duration of treatment or an increase in propranolol concentration. A previous study demonstrated that propranolol inhibited the proliferation, invasion and migration of MCF7, HT-29 and HepG2 cells (26). However, since propranolol inhibited tumor cell proliferation, it was necessary to ensure that the drug did not affect normal cell function while inhibiting tumor cell proliferation. Therefore, the determination of the optimal dose of propranolol is necessary in cellular and clinical studies. The effect of propranolol was studied with eight different concentrations, ranging from 2.5 to $320 \mu \mathrm{mol} / 1$. The results demonstrated that propranolol at low concentrations demonstrated no significant influence on cell proliferation and that propranolol at the highest concentrations led to cell death. Treatment with 40 and $80 \mu \mathrm{mol} / 1$ propranolol demonstrated significant inhibitory effect on HepG2 and HepG2.2.15 cells while demonstrating no influence on normal liver cells.

Furthermore, the present study confirmed that propranolol induced apoptosis of HepG2 and HepG2.2.15 cells and resulted in the S-phase arrest of these cells. A previous study demonstrated that propranolol induced cell cycle arrest and cell apoptosis in melanoma cells (29). It was also identified in the present study that propranolol induced morphological alterations in the nuclei of liver cancer cells during the process of apoptosis, and stimulated the formation of apoptotic bodies. The apoptotic rate of liver cancer cells increased with the increase in the concentration of propranolol, while the drug did not affect the apoptotic rate of HL-7702 cells. Furthermore, it was demonstrated that propranolol induced the apoptosis of liver cancer cells by promoting caspase-dependent signaling, which may provide a direction for further research. Anti-tumor drugs include cell cycle-specific and cell cycle-non-specific drugs; the data of the present study demonstrated that the effect of propranolol on liver cancer cells is cell cycle-specific, and led to a significant increase in the percentage of HepG2 and HepG2.2.15 cells in the $\mathrm{S}$ phase, indicating that cells were arrested at the $\mathrm{S}$ phase. Clinically, commonly available anti-tumor drugs that affect $\mathrm{S}$ phase progression include fluorouracil and methotrexate. Whether the anti-tumor effect of propranolol is also achieved by targeting the $\mathrm{S}$ phase requires further investigation.

The above results indicate that $80 \mu \mathrm{mol} / 1$ is the optimum dose of propranolol for studying anti-tumor effects in liver cancer cells. Propranolol at $80 \mu \mathrm{mol} / 1$ inhibited cell proliferation and induced apoptosis to the greatest extent without affecting the biological function of HL-7702 cells.

HepG2.2.15 cells demonstrated greater resistance to propranolol compared with the HepG2 cells. The HepG2.2.15 cell line expresses the HBV antigen and secretes complete HBV particles, and therefore can serve as a cellular model for HBV-associated liver cancer. The present study demonstrated that the proliferation ratio of HepG2 and HepG2.2.15 cells started to significantly decline following treatment with 20 and $40 \mu \mathrm{mol} / 1$ propranolol, respectively. Microscopic observation demonstrated that the alterations in HepG2.2.15 were not as evident as in HepG2 cells following incubation with the same concentration of propranolol. Compared with HepG2 cells, the decrease in expression of ADRB2 and the apoptotic rate were lower in HepG2.2.15 cells following the incubation with propranolol $(\mathrm{P}<0.05)$. HepG2.2.15 cells required a larger dose of propranolol to induce the same effect as in HepG2 cells. Future studies should aim to determine whether HepG2.2.15 cells are more resistant to propranolol due to the HBV infection, whether an increased dose of propranolol will be required when treating $\mathrm{HBV}$-associated liver cancers in patients, and whether the use of anti-HBV drugs could reduce the difficulty in treating $\mathrm{HBV}$-associated liver cancer.

There are certain limitations associated with the present study; although it was demonstrated that propranolol could inhibit the proliferation of liver cancer cells and induce their 
apoptosis, and that the apoptosis induced by propranolol maybe activated by caspase-dependent signaling, the mechanism underlying the anti-tumor effect of propranolol was not elucidated. Therefore, the mechanisms of the anti-tumor effect of propranolol should be elucidated in future studies.

In conclusion, the expression of $\beta$ receptors, primarily ADRB2, in HepG2 and HepG2.2.15 cells was markedly higher than in HL-7702 cells; this was reduced by treatment with propranolol. Propranolol inhibited proliferation, and induced apoptosis and S-phase arrest in liver cancer cells. Further investigation of the role of the inhibition of $\beta$ adrenergic receptor signaling in liver cancer cells is required. The possible mechanisms underlying the anti-tumor effect of propranolol and the pathogenesis of liver cancer need to be elucidated to provide novel insights into the development of adjuvant therapies for liver cancer.

\section{Acknowledgements}

The present study was supported by grants from the National Natural Science Foundation of China (grant nos. 81673651 and 81273552), the Major Projects of the Ministry of Science and Technology of China (grant no. 2017ZX10302202) and Tianjin Municipal Health and Family Planning Commission (grant nos. 16KG151 and 2014KY03).

\section{References}

1. Torre LA, Bray F, Siegel RL, Ferlay J, Lortet-Tieulent J and Jemal A: Global cancer statistics, 2012. CA Cancer J Clin 65: 87-108, 2015

2. Chen W, Zheng R, Baade PD, Zhang S, Zeng H, Bray F, Jemal A, Yu XQ and He J: Cancer statistics in China, 2015. CA Cancer J Clin 66: 115-132, 2016.

3. Cole SW and Sood AK: Molecular pathways: Beta-adrenergic signaling in cancer. Clin Cancer Res 18: 1201-1206, 2012.

4. Maccari S, Buoncervello M, Rampin A, Spada M, Macchia D, Giordani L, Stati T, Bearzi C, Catalano L, Rizzi R, et al: Biphasic effects of propranolol on tumour growth in B16F10 melanoma-bearing mice. Br J Pharmacol 174: 139-149, 2017.

5. Montoya A, Amaya CN, Belmont A, Diab N, Trevino R, Villanueva G, Rains S, Sanchez LA, Badri N, Otoukesh S, et al: Use of non-selective beta-blockers is associated with decreased tumor proliferative indices in early stage breast cancer. Oncotarget 8: 6446-6460, 2017.

6. Wilson JM, Lorimer E, Tyburski MD and Williams CL: $\beta$-Adrenergic receptors suppress Rap1B prenylation and promote the metastatic phenotype in breast cancer cells. Cancer Biol Ther 16: 1364-1374, 2015.

7. Wei WJ, Shen CT, Song HJ, Qiu ZL and Luo QY: Propranolol sensitizes thyroid cancer cells to cytotoxic effect of vemurafenib. Oncol Rep 36: 1576-1584, 2016.

8. Sorski L, Melamed R, Matzner P, Lavon H, Shaashua L, Rosenne E and Ben-Eliyahu S: Reducing liver metastases of colon cancer in the context of extensive and minor surgeries through $\beta$-adrenoceptors blockade and COX2 inhibition. Brain Behav Immun 58: 91-98, 2016.

9. Partecke LI, Speerforck S, Kading A, Seubert F, Kuhn S, Lorenz E, Schwandke S, Sendler M, Kessler W, Trung DN, et al: Chronic stress increases experimental pancreatic cancer growth, reduces survival and can be antagonised by beta-adrenergic receptor blockade. Pancreatology 16: 423-433, 2016.

10. Cardwell CR, Pottegard A, Vaes E, Garmo H, Murray LJ, Brown C, Vissers PA, O'Rorke M, Visvanathan K, Cronin-Fenton D, et al: Propranolol and survival from breast cancer: A pooled analysis of European breast cancer cohorts. Breast Cancer Res 18: 119, 2016.

11. Hoeger PH, Harper JI, Baselga E, Bonnet D, Boon LM, Ciofi Degli Atti M, El Hachem M, Oranje AP, Rubin AT, Weibel L and Leaute-Labreze C: Treatment of infantile haemangiomas: Recommendations of a European expert group. Eur J Pediatr 174: $855-865,2015$
12. Garcia-Tsao G, Sanyal AJ, Grace ND and Carey W; Practice Guidelines Committee of the American Association for the Study of Liver D, Practice Parameters Committee of the American College of G. Prevention and management of gastroesophageal varices and variceal hemorrhage in cirrhosis. Hepatology 46: 922-938, 2007.

13. Livak KJ and Schmittgen TD: Analysis of relative gene expression data using real-time quantitative PCR and the 2(-Delta Delta C(T)) method. Methods 25: 402-408, 2001.

14. Rico M, Baglioni M, Bondarenko M, Laluce NC, Rozados V, Andre N, Carre M, Scharovsky OG and Menacho Marquez M: Metformin and propranolol combination prevents cancer progression and metastasis in different breast cancer models. Oncotarget 8: 2874-2889, 2017.

15. Hwa YL, Shi Q, Kumar SK, Lacy MQ, Gertz MA, Kapoor P, Buadi FK, Leung N, Dingli D, Go RS, et al: Beta-blockers improve survival outcomes in patients with multiple myeloma: A retrospective evaluation. Am J Hematol 92: 50-55, 2017.

16. Chang PY, Huang WY, Lin CL, Huang TC, Wu YY, Chen JH and Kao CH: Propranolol reduces cancer risk: A population-based cohort study. Medicine (Baltimore) 94: e1097, 2015.

17. Pantziarka P, Bouche G, Sukhatme V, Meheus L, Rooman I and Sukhatme VP: Repurposing drugs in oncology (ReDO)propranolol as an anti-cancer agent. Ecancermedicalscience 10: 680, 2016

18. Thiele M, Wiest R, Gluud LL, Albillos A and Krag A: Can non-selective beta-blockers prevent hepatocellular carcinoma in patients with cirrhosis? Med Hypotheses 81: 871-874, 2013.

19. Herrera I, Pascual S, Zapater P, Carnicer F, Bellot P and María Palazón J: The use of $\beta$-blockers is associated with a lower risk of developing hepatocellular carcinoma in patients with cirrhosis. Eur J Gastroenterol Hepatol 28: 1194-1197, 2016.

20. Hu HH, Liu J, Lin YL, Luo WS, Chu YJ, Chang CL, Jen CL, Lee MH, Lu SN, Wang LY, et al: The rs2296651 (S267F) variant on NTCP (SLC10A1) is inversely associated with chronic hepatitis B and progression to cirrhosis and hepatocellular carcinoma in patients with chronic hepatitis B. Gut 65: 1514-1521, 2016.

21. Cavuoto J: Neurotech report. Neuromodulation 14: 103, 2011.

22. Lee HS, Chung YH and Kim CY: Specificities of serum alpha-fetoprotein in HBsAg+ and HBsAg- patients in the diagnosis of hepatocellular carcinoma. Hepatology 14: 68-72, 1991.

23. Lopez-Terrada D, Cheung SW, Finegold MJ and Knowles BB: Hep G2 is a hepatoblastoma-derived cell line. Hum Pathol 40: $1512-1515,2009$.

24. Kassahun WT, Guenl B, Ungemach FR, Jonas S and Abraham G: Expression and functional coupling of liver $\beta 2$-adrenoceptors in the human hepatocellular carcinoma. Pharmacology 89: 313-320, 2012.

25. Bevilacqua M, Norbiato G, Chebat E, Baldi G, Bertora P, Regalia E, Colella G, Gennari L and Vago T: Changes in alpha-1 and beta-2 adrenoceptor density in human hepatocellular carcinoma. Cancer 67: 2543-2551, 1991.

26. Iseri OD, Sahin FI, Terzi YK, Yurtcu E, Erdem SR and Sarialioglu F: Beta-Adrenoreceptor antagonists reduce cancer cell proliferation, invasion and migration. Pharm Biol 52: 1374-1381, 2014.

27. Zhang ZF, Feng XS, Chen H, Duan ZJ, Wang LX, Yang D, Liu PX, Zhang QP, Jin YL, Sun ZG and Liu H: Prognostic significance of synergistic hexokinase-2 and beta2-adrenergic receptor expression in human hepatocelluar carcinoma after curative resection. BMC Gastroenterol 16: 57, 2016.

28. Wu FQ, Fang T, Yu LX, Lv GS, Lv HW, Liang D, Li T, Wang CZ, Tan YX, Ding J, et al: ADRB2 signaling promotes HCC progression and sorafenib resistance by inhibiting autophagic degradation of HIF1 $\alpha$. J Hepatol 65: 314-324, 2016.

29. Zhou C, Chen X, Zeng W, Peng C, Huang G, Li X, Ouyang Z, Luo Y, Xu X, Xu B, et al: Propranolol induced G0/G1/S phase arrest and apoptosis in melanoma cells via AKT/MAPK pathway. Oncotarget 7: 68314-68327, 2016.

This work is licensed under a Creative Commons Attribution-NonCommercial-NoDerivatives 4.0 International (CC BY-NC-ND 4.0) License. 